\title{
Idiopathic Pulmonary Fibrosis and Diffuse Parenchymal Lung Disease: Implications from Initial Experience with ${ }^{18}$ F-FDG PET/CT
}

\begin{abstract}
Ashley M. Groves ${ }^{1}$, Thida Win ${ }^{2}$, Nicholas J. Screaton ${ }^{3}$, Marko Berovic ${ }^{1}$, Raymondo Endozo ${ }^{1}$, Helen Booth ${ }^{4}$,
\end{abstract} Irfan Kayani $^{1}$, Leon J. Menezes ${ }^{1}$, John C. Dickson ${ }^{1}$, and Peter J. Ell ${ }^{1}$

${ }^{1}$ Institute of Nuclear Medicine, University College London, London, United Kingdom; ${ }^{2}$ Respiratory Medicine, Lister Hospital, Stevenage, United Kingdom; ${ }^{3}$ Department of Radiology, Papworth Hospital, Cambridge, United Kingdom; and ${ }^{4}$ Department of Thoracic Medicine, University College London Hospital, London, United Kingdom

The purpose of this study was to evaluate integrated ${ }^{18} \mathrm{~F}-\mathrm{FDG}$ $\mathrm{PET} / \mathrm{CT}$ in patients with idiopathic pulmonary fibrosis (IPF) and diffuse parenchymal lung disease (DPLD). Methods: Thirty-six consecutive patients ( 31 men and 5 women; mean age $\pm S D$, $68.7 \pm 9.4$ y) with IPF $(n=18)$ or other forms of DPLD $(n=18)$ were recruited for PET/CT and high-resolution CT (HRCT), acquired on the same instrument. The maximal pulmonary ${ }^{18} \mathrm{~F}-$ FDG metabolism was measured as a standardized uptake value $\left(\mathrm{SUV}_{\text {max }}\right)$. At this site, the predominant lung parenchyma HRCT pattern was defined for each patient: ground-glass or reticulation/honeycombing. Patients underwent a global health assessment and pulmonary function tests. Results: Raised pulmonary ${ }^{18} \mathrm{~F}-\mathrm{FDG}$ metabolism in 36 of 36 patients was observed. The parenchymal pattern on HRCT at the site of maximal ${ }^{18} \mathrm{~F}-\mathrm{FDG}$ metabolism was predominantly ground-glass (7/36), reticulation/ honeycombing (26/36), and mixed (3/36). The mean SUV $\mathrm{Sax}_{\text {in }}$ patients with ground-glass and mixed patterns was $2.0 \pm$ 0.4 , and in reticulation/honeycombing it was $3.0 \pm 1.0$ (MannWhitney $U$ test, $P=0.007)$. The mean $S_{\text {max }}$ in patients with IPF was $2.9 \pm 1.1$, and in other DPLD it was $2.7 \pm 0.9$ (MannWhitney $U$ test, $P=0.862)$. The mean mediastinal lymph node SUV $_{\max }(2.7 \pm 1.3)$ correlated with pulmonary $\operatorname{SUV}_{\max }(r=$ $0.63, P<0.001)$. Pulmonary ${ }^{18} \mathrm{~F}-\mathrm{FDG}$ uptake correlated with the global health score $(r=0.50, P=0.004)$, forced vital capacity $(r=0.41, P=0.014)$, and transfer factor $(r=0.37, P=0.042)$. Conclusion: Increased pulmonary ${ }^{18} \mathrm{~F}-\mathrm{FDG}$ metabolism in all patients with IPF and other forms of DPLD was observed. Pulmonary ${ }^{18} \mathrm{~F}-\mathrm{FDG}$ uptake predicts measurements of health and lung physiology in these patients. ${ }^{18} \mathrm{~F}-\mathrm{FDG}$ metabolism was higher when the site of maximal uptake corresponded to areas of reticulation/honeycomb on HRCT than to those with ground-glass patterns.

Key Words: lung diseases; interstitial; positron emission tomography; cone-beam computed tomography

J Nucl Med 2009; 50:538-545

DOI: 10.2967/jnumed.108.057901

Received Oct. 2, 2008; revision accepted Jan. 6, 2009.

For correspondence or reprints contact: Thida Win, Respiratory Medicine,

Lister Hospital, Coreys Mill Lane, Stevenage, Hertfordshire, SG1 4AB.

E-mail: drthidawin@hotmail.com

COPYRIGHT ๑ 2009 by the Society of Nuclear Medicine, Inc.
D iffuse parenchymal lung disease (DPLD) has a major clinical impact on those affected. Prognosis is variable; patients with idiopathic pulmonary fibrosis (IPF) have progressive dyspnea and a median survival of just 36 mo. DPLD covers a wide spectrum of disease, and currently diagnosis is based on a combination of clinical, physiologic, radiologic, and, if necessary, histopathologic criteria. Despite advances in medical therapy and technology, the prognosis in IPF remains stubbornly poor, and the need for progress and new approaches is acute. The lack of progress reflects the poorly understood etiology and pathogenesis of DPLD and IPF (1-6).

High-resolution CT (HRCT) is the current imaging reference standard in the investigation of patients with DPLD, revealing structural detail of the entire lung parenchyma that corresponds to pathologic specimens. The pattern and distribution of parenchymal abnormalities on HRCT provide insight into the underlying histology. Indeed, characteristic HRCT features have been so successful at predicting the histology in IPF (positive predictive value, $96 \%$ (7)) that current guidelines do not recommend lung biopsy, except in a few atypical cases (1). However, HRCT is a purely structural imaging technique on which only indirect inferences regarding metabolism can be made. PET offers the ability to noninvasively investigate cellular metabolism in vivo. PET studies on animals and in vitro have yielded some insights into the biology of DPLD (8-10). Recent technologic advances have led to the integration of PET with CT, allowing molecular imaging to be combined with the fine structural detail of CT. PET/CT has profoundly affected the management of cancer (11); however, to date PET/CT has not been applied to IPF and DPLD.

Here, we describe the first, to our knowledge, prospective study of combined ${ }^{18} \mathrm{~F}$-FDG PET/CT evaluation in IPF and other forms of DPLD. In addition, we sequentially per- 
formed HRCT on the same PET/CT instrument to gain in vivo insight on lung parenchyma changes at sites of abnormal pulmonary metabolism.

\section{MATERIALS AND METHODS}

\section{Patients}

Institutional Review Board permission and informed patient consent were obtained for this prospective study. Over 15 mo, 36 consecutive patients ( 31 men, 5 women; mean age $\pm \mathrm{SD}, 68.7 \pm$ 9.4 y) with diagnosed DPLD were recruited. All patients were diagnosed after clinical assessment, pulmonary function tests (PFTs), expert HRCT evaluation, and a minimum of 3 mo of follow-up after the PET/CT study. Diagnostic criteria and patient management strictly adhered to the recommendations of the American Thoracic Society/European Respiratory Society International Multidisciplinary Consensus Classification of the Idiopathic Interstitial Pneumonias (1). Patients with IPF were defined as those with a usual interstitial pneumonia (UIP) HRCT pattern and had no associated cause for their interstitial pulmonary disease, such as collagen vascular disease, chemo- or radiotherapy, dust exposures, and others. If patients did not meet these criteria, they were grouped together as other forms of DPLDs. In keeping with the guidelines (1), biopsies were performed only when there were atypical findings resulting in a doubt in diagnosis.

Of the 36 study patients, 18 had IPF (16 men, 2 women; mean age, $70.9 \pm 7.7 \mathrm{y}$ ); a clinical profile is summarized in Table 1. In 1 of these IPF patients, a lung biopsy was required to confirm the diagnosis of UIP. The remaining 18 patients had other forms of DPLD (15 men, 3 women; mean age, $66.6 \pm 10.7$ y); the clinical profile is summarized in Table 2. Biopsy was performed in 3 of these 18 patients, showing nonspecific pneumonitis in 2 and cryptogenic organizing pneumonia in 1 patient.
To make a semiquantitative assessment of patient health, the general health score (a scale of 1-5; lower scores equate to better health) used in the St. Georges Quality of Life Questionnaire (12) was applied at the time of the PET/CT study.

\section{Imaging}

All patients fasted for $6 \mathrm{~h}$. Images were acquired $1 \mathrm{~h}$ after an injection of ${ }^{18} \mathrm{~F}-\mathrm{FDG}(200 \mathrm{MBq})$ on a dedicated combined PET/ 64-detector CT scanner (GE Healthcare Technology). In total, 3 sequential images of the thorax were obtained while the patient remained supine on the table throughout the procedure. First, a (attenuation-correction) CT was performed using $64 \times 3.75 \mathrm{~mm}$ detectors, a pitch of 1.5 , and a $5-\mathrm{mm}$ collimation $(140 \mathrm{kVp}$ and $80 \mathrm{~mA}$ in $0.8 \mathrm{~s}$ ). The patient's position was maintained while a whole-body ${ }^{18} \mathrm{~F}$-FDG PET emission scan was acquired, covering an area identical to that covered by the CT. All images were acquired in 2-dimensional mode ( $8 \mathrm{~min} / \mathrm{bed}$ position). Transaxial emission images of 3.27-mm thickness (pixel size, $3.9 \mathrm{~mm}$ ) were reconstructed using ordered-subsets expectation maximization with 2 iterations and 28 subsets. The axial field of view was $148.75 \mathrm{~mm}$, resulting in 47 slices per bed position. Next, a deep inspiratory HRCT was performed while maintaining the patient's position, using $64 \times 1.25 \mathrm{~mm}$ detectors, a pitch of 0.53 , and a $1.25-\mathrm{mm}$ collimation (120 kVp and $100 \mathrm{mAs})$.

\section{Image Analysis}

PET/CT images were reviewed by 2 combined radiologist/ nuclear medicine physicians in consensus. One of these readers had a specialist interest in cardiothoracic PET/CT ( $>5 \mathrm{y})$. PET/CT images were loaded onto a Xeleris workstation (GE Healthcare Technology). Both attenuation- and non-attenuation-corrected images were reviewed visually (Fig. 1) using similar methodology previously described (13) to ensure that areas of higher-density lung were not inducing attenuation-correction artifacts. The area

TABLE 1. Clinical Profile of Study Patients with IPF

\begin{tabular}{|c|c|c|c|c|c|c|c|c|}
\hline Patient no. & Smoker & TLC $^{*}$ & $\mathrm{FEV}_{1}$ & $\mathrm{TL}_{\mathrm{CO}}$ & $\mathrm{HRCT}$ & Treated & Comorbidity & $\mathrm{SUV}_{\max }$ \\
\hline 1 & $x$ & 71 & 68 & 65 & UIP & $\mathrm{N}$ & None & 3.2 \\
\hline 2 & $\mathrm{X}$ & 75 & 68 & 38 & UIP & $\mathrm{N}$ & COPD & 1.5 \\
\hline 3 & $\mathrm{X}$ & 57 & 74 & 42 & UIP & $\mathrm{N}$ & None & 3.2 \\
\hline 4 & $\mathrm{~N}$ & 58 & 94 & 59 & UIP & $\mathrm{N}$ & Cardiac & 2 \\
\hline 5 & $X$ & 69 & 92 & 56 & UIP & $\mathrm{N}$ & None & 1.8 \\
\hline 6 & $\mathrm{X}$ & 72 & 40 & 51 & UIP & $N$ & None & 2.2 \\
\hline 7 & $\mathrm{X}$ & 59 & 74 & 49 & UIP & $\mathrm{N}$ & None & 2 \\
\hline 8 & Y & 60 & 84 & 49 & UIP & $N$ & None & 2.2 \\
\hline 9 & $\mathrm{~N}$ & 43 & 50 & 29 & UIP & $\mathrm{N}$ & None & 2 \\
\hline 10 & $x$ & 70 & 80 & 59 & UIP & $\mathrm{N}$ & None & 2.9 \\
\hline 11 & $X$ & - & 78 & - & UIP & $\mathrm{N}$ & None & 5.4 \\
\hline 12 & $x$ & 50 & 71 & 35 & UIP & N & None & 4.4 \\
\hline 13 & $\mathrm{~N}$ & - & 48 & - & UIP & $N$ & None & 4.9 \\
\hline 14 & $x$ & - & 97 & 62 & UIP & $\mathrm{N}$ & COPD & 1.9 \\
\hline 15 & $\mathrm{~N}$ & 89 & 89 & 42 & UIP & $N$ & None & 2.4 \\
\hline 16 & $x$ & 70 & 76 & 51 & UIP & $N$ & None & 2.8 \\
\hline 17 & $\mathrm{~N}$ & 73 & 75 & 75 & UIP & $\mathrm{N}$ & Cardiac & 1.9 \\
\hline 18 & $x$ & 63 & 26 & 34 & UIP & $N$ & None & 3.6 \\
\hline $\begin{array}{l}{ }^{*} \text { PFTs are } \\
\text { X = ex-sm } \\
\text { These pati } \\
\text { disease, med } \\
\text { were not com }\end{array}$ & $\begin{array}{l}\text { tage prec } \\
\mathrm{N}=\text { no; } \\
\text { dd typical } \\
\text {, radiothe } \\
\text { typical, }\end{array}$ & $\begin{array}{l}\text {; TLC } \\
\text { and } p \\
\text { hd du } \\
\text { refore }\end{array}$ & $\begin{array}{l}\text { al lung } \\
\text { ogic da } \\
\text { osures } \\
\text { linical }\end{array}$ & $\begin{array}{l}\text { ity. } \\
\text { FF, incl } \\
\text { /pical } \\
\text { s, pati }\end{array}$ & $\begin{array}{l}\text { xclusio } \\
\text { earanc } \\
\text { erwent }\end{array}$ & $\begin{array}{l}\text { her cause } \\
\text { HRCT we } \\
y \text {, which }\end{array}$ & $\begin{array}{l}\text { LPD such as c } \\
\text { erved (1). Finc } \\
\text { d UIP. }\end{array}$ & $\begin{array}{l}\text { tive tissue } \\
1 \text { patient }\end{array}$ \\
\hline
\end{tabular}


TABLE 2. Clinical Profile of Study Patients with Other Forms of DPLD

\begin{tabular}{|c|c|c|c|c|c|c|c|c|}
\hline Patient no. & Smoker & TLC $^{*}$ & $\mathrm{FEV}_{1}$ & $\mathrm{TL}_{\mathrm{CO}}$ & UIP & Treated & Comorbidity & $\mathrm{SUV}_{\max }$ \\
\hline 1 & $X$ & 67 & 59 & 27 & $\mathrm{~N}$ & $\mathrm{~N}$ & Rheumatoid & 5.4 \\
\hline 2 & $x$ & 102 & 79 & 55 & $\mathrm{~N}$ & $\mathrm{~N}$ & None & 2.2 \\
\hline 3 & $X$ & 73 & 91 & 64 & $\mathrm{~N}$ & $\mathrm{Y}^{\dagger}$ & Sjögren & 2.5 \\
\hline 4 & $X$ & 76 & 82 & 53 & $\mathrm{~N}$ & $\mathrm{~N}$ & Asbestosis & 2.1 \\
\hline 5 & $X$ & 62 & 57 & 47 & $\mathrm{~N}$ & $\mathrm{~N}$ & Crohn & 2.5 \\
\hline 6 & $x$ & 96 & 95 & 78 & $\mathrm{~N}$ & $\mathrm{~N}$ & Asbestosis & 1.9 \\
\hline 7 & $x$ & 68 & 100 & 49 & $\mathrm{~N}$ & $\mathrm{~N}$ & None & 3.4 \\
\hline 8 & $\mathrm{~N}$ & 55 & 43 & 33 & $\mathrm{~N}$ & $\mathrm{Y}^{\dagger}$ & None & 2 \\
\hline 9 & $X$ & 55 & 75 & 44 & $\mathrm{~N}$ & $\mathrm{Y}^{\ddagger}$ & Asbestosis & 3.1 \\
\hline 10 & $x$ & 48 & 78 & 72 & $\mathrm{~N}$ & Y§ & Rheumatoid & 3.1 \\
\hline 11 & $X$ & 48 & 72 & 61 & Y & $Y \|$ & Rheumatoid & 3.1 \\
\hline 12 & $\mathrm{~N}$ & - & 14 & - & $\mathrm{N}$ & $\mathrm{N}$ & None & 2.7 \\
\hline 13 & $X$ & - & 76 & - & $\mathrm{N}$ & $\mathrm{N}$ & Rheumatoid & 3.3 \\
\hline 14 & $\mathrm{Y}$ & - & 106 & 45 & Y & Yq1 & Rheumatoid & 3.3 \\
\hline 15 & $x$ & 72 & 83 & & $\mathrm{~N}$ & $\mathrm{~N}$ & None & 3.4 \\
\hline 16 & $X$ & 69 & 81 & 54 & $\mathrm{~N}$ & $\mathrm{~N}$ & Cardiac & 2.9 \\
\hline 17 & $\mathrm{Y}$ & - & 38 & - & $\mathrm{N}$ & $\mathrm{N}$ & None & 1.9 \\
\hline 18 & Y & 86 & 71 & 96 & $\mathrm{~N}$ & $\mathrm{~N}$ & Cardiac & 2.4 \\
\hline \multicolumn{9}{|c|}{ 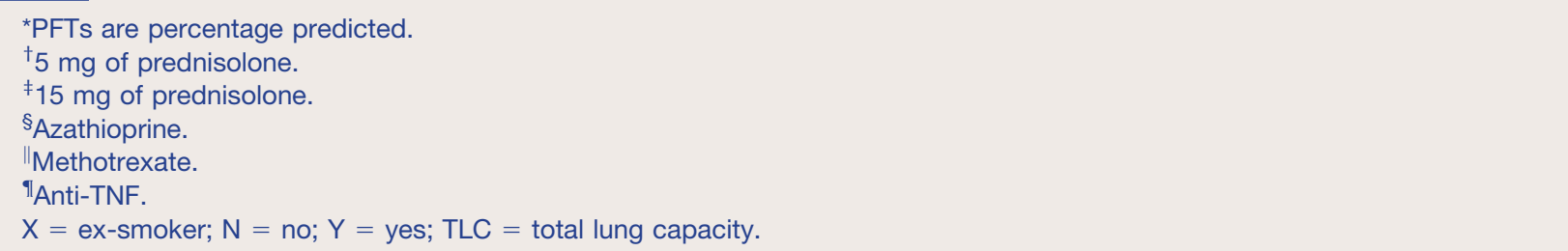 } \\
\hline
\end{tabular}

of most intense pulmonary ${ }^{18} \mathrm{~F}$-FDG uptake was identified and measured (maximum standardized uptake value $\left[\mathrm{SUV}_{\max }\right]$ ), and the HRCT parenchymal pattern in the region was assessed. In addition, the $\mathrm{SUV}_{\max }$ in areas of minimal uptake with normal lung parenchyma (confirmed on HRCT) was used to determine the background lung uptake, and in turn the target-to-background ratio (TBR) was calculated. The predominant distribution of pulmonary ${ }^{18} \mathrm{~F}$-FDG uptake was classified as diffuse, peripheral, or central in the transverse plane and as upper or lower zone or diffuse in the craniocaudal plane. Maximal uptake of ${ }^{18} \mathrm{~F}-\mathrm{FDG}$ in mediastinal or hilar lymph nodes was also recorded. To assess interobserver variability of the pulmonary SUV measurements, images from the first 10 PET/CT studies were reanalyzed by a third PET reader.

The HRCT images were reconstructed using soft-tissue and high-spatial-frequency reconstruction algorithms. The images were then loaded into a proprietary workstation (A/W CT Workstation; GE Healthcare) and reviewed by a thoracic radiologist with a specialist interest in HRCT ( $>10 \mathrm{y}$ of experience), without detailed knowledge of the PET images. The radiologist had access to the full HRCT dataset but was given PET/CT images of only the sites of interest identified by the PET reporters. The lung parenchyma in the region of the maximal pulmonary ${ }^{18} \mathrm{~F}-\mathrm{FDG}$ uptake was examined for the presence of ground-glass opacity, reticulation, honeycombing, and architectural distortion or traction bronchiectasis, and thus the predominant pattern was determined: ground-glass predominant $(14,15)$, reticulation/honeycombing predominant $(15,16)$, or mixed $(17,18)$. The pattern and distribution of abnormalities on the full HRCT dataset were classified into typical UIP appearances or other (15-18), and the distribution was classified as diffuse, peripheral, or central in the transverse plane and as upper or lower zone or diffuse in the craniocaudal plane. In addition, the HRCT images were used to confirm the presence of normal parenchyma at the site chosen for measuring background.

\section{Image Registration}

PET/CT and HRCT images were aligned on an Advantage Workstation (GE Healthcare). Because the acquisition protocol differed for the PET/CT (shallow breathing) versus the HRCT (deep inhalation breath-hold), direct correspondence was not always guaranteed. However, areas of ${ }^{18} \mathrm{~F}-\mathrm{FDG}$ uptake and parenchymal lung damage were easily identified visually, and

FIGURE 1. (A) Axial attenuation-corrected ${ }^{18} \mathrm{~F}-\mathrm{FDG}$ PET. Non-attenuationcorrected ${ }^{18}$ F-FDG PET (B) and CT (C) of patient with pulmonary fibrosis. Increased ${ }^{18}$ F-FDG uptake associated with lung parenchymal abnormality is similar in appearance on both corrected and noncorrected image and therefore is not artifact induced by attenuation correction.
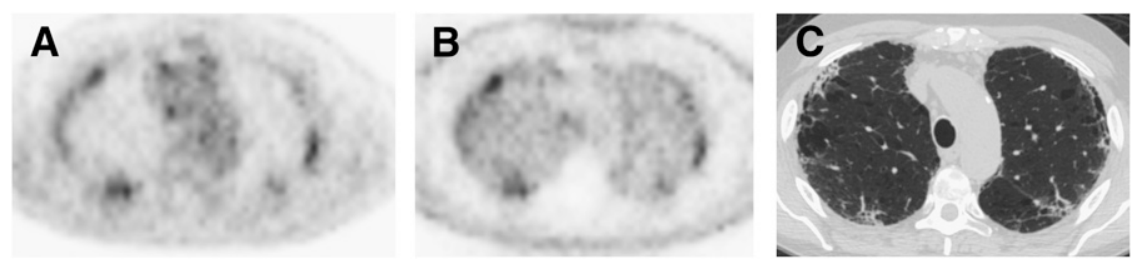

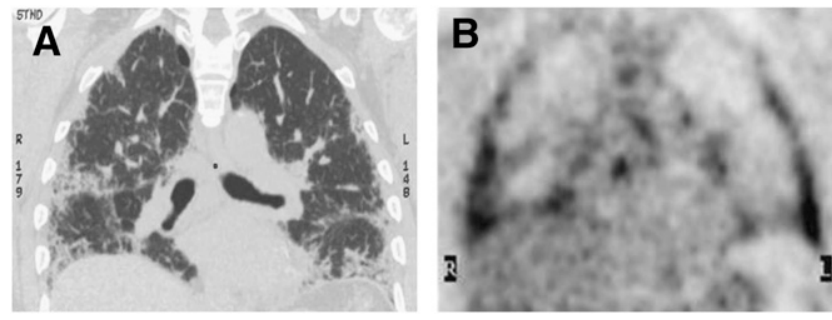

FIGURE 2. Coronal fused ${ }^{18} \mathrm{~F}-\mathrm{FDG}$ PET/CT images of 71$y$-old man with clinical and conventional radiologic features of IPF. Areas of lung parenchymal abnormality on CT correspond to areas of raised ${ }^{18} \mathrm{~F}-\mathrm{FDG}$ on PET: there is posterolateral distribution, like most cases in this study. CT component of study has been reconstructed with highfrequency algorithm and displayed to show maximum lung parenchymal detail.

alignment was achieved by selecting the slices that achieved best visual correspondence based on identifiable anatomic landmarks such as parenchymal pattern and thoracic wall (Figs. 1-5). At the site of most intense pulmonary ${ }^{18}$ F-FDG uptake as quantified by the $\mathrm{SUV}_{\text {max }}$, the thoracic radiologist reported the HRCT findings as ground-glass, reticulation, or mixed (14-18) as described above.

\section{Statistical Analysis}

Interobserver agreement was assessed by Bland-Altman statistics. Normality was assessed using Kolmogorov-Smirnov testing. Mann-Whitney $U$ tests were performed to compare $S_{U} V_{\max }$ values between different groups of DPLD patients and to compare pulmonary $\mathrm{SUV}_{\max }$ between patients with different HRCT parenchymal patterns. Pearson correlation was used to compare pulmonary ${ }^{18}$ F-FDG uptake with pulmonary function tests. Spearman rank correlation was performed to investigate possible correlation between pulmonary $\mathrm{SUV}_{\max }$ with mediastinal nodal uptake and global health score. Statistical significance was set at 5\%. All statistical tests were performed using software from GraphPad.

\section{RESULTS}

\section{Patient Global Health Score}

Thirty-two of 36 patients completed the global health assessment. The correlation $(r)$ between pulmonary $\mathrm{SUV}_{\max }$ and global health score was $0.50(P=0.004)$.

\section{Patient Pulmonary Function}

The correlation $(r)$ between $\mathrm{SUV}_{\max }$ and percentage predicted forced expiratory volume in $1 \mathrm{~s}\left(\mathrm{FEV}_{1}\right)$ was
$0.17(P=0.325)$. The correlation $(r)$ between pulmonary $\mathrm{SUV}_{\text {max }}$ and percentage predicted forced vital capacity was $0.41(P=0.014)$. The correlation $(r)$ between pulmonary $\mathrm{SUV}_{\text {max }}$ and percentage predicted diffusion capacity (percentage predicted $\left.\mathrm{TL}_{\mathrm{CO}}\right)$ was $0.37(P=0.042)$.

\section{Patterns and Distributions of Pulmonary ${ }^{18}$ F-FDG Metabolism and Parenchymal Abnormalities}

All (36/36) patients exhibited focal raised pulmonary ${ }^{18} \mathrm{~F}-\mathrm{FDG}$ metabolism, and the predominant distribution of raised pulmonary ${ }^{18} \mathrm{~F}-\mathrm{FDG}$ corresponded to the regional predominance of lung parenchymal abnormality (Figs. 2-4). The predominant distribution of both ${ }^{18} \mathrm{~F}-\mathrm{FDG}$ metabolism on PET and abnormality on HRCT was basal or peripheral in 33 of 36 patients, central in 1 of 36 patients, and diffuse in 2 of 36 patients. The mean $\mathrm{SUV}_{\max }$ of normal lung confirmed on HRCT was 0.7 (the quoted value of Vera et al. (19) for normal lung $\mathrm{SUV}_{\max }$ was 0.6).

\section{${ }^{18}$ F-FDG Metabolism and Parenchymal Patterns in Region of Interest of Maximal ${ }^{18}$ F-FDG Uptake}

At the site of most intense pulmonary ${ }^{18} \mathrm{~F}$-FDG uptake, the mean $\mathrm{SUV}_{\max }$ was 2.8 (range, 1.4-5.4), and the mean TBR was 4.1 (range, 2.2-8.2). At the site of maximal ${ }^{18} \mathrm{~F}$ FDG metabolism, the corresponding lung parenchyma on HRCT was ground-glass in 7 of 36 patients, reticulation/ honeycombing in 26 of 36 patients, and mixed in 3 of 36 patients. The mean $\mathrm{SUV}_{\max }$ in patients with ground-glass or mixed predominance was $2.1 \pm 0.4$, and in those with a reticulation/honeycombing predominance it was $3.0 \pm 1.0$ (Mann-Whitney $U$ test, $P=0.007$ ). The mean TBR in patients with a ground-glass or mixed predominance was $3.5 \pm 0.7$, and in those with a reticulation/honeycombing predominance it was $4.2 \pm 1.4$ (Mann-Whitney U test, $P=$ $0.403)$. Interobserver agreement in determining the pulmonary $\mathrm{SUV}_{\max }$ was good, with a mean difference of $0(-0.06$ to +0.06$)($ Fig. 5).

\section{Mediastinal Lymph Nodes}

The mean $\mathrm{SUV}_{\max }$ of the most avid mediastinal or hilar node was $2.7 \pm 1.3$, and 32 of 36 patients had an $\mathrm{SUV}_{\max }$ greater than 2.0. The patient distribution of the thoracic ${ }^{18} \mathrm{~F}-\mathrm{FDG}$ maximal lymph node uptake is summarized in Tables 3 and 4. Significant correlation between pulmonary
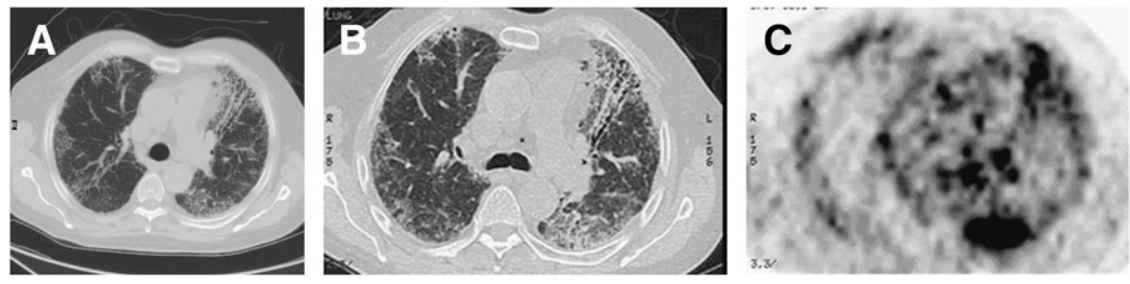

\footnotetext{
${ }^{18}$ F-FDG PET/CT images (B and C) show that lung parenchymal abnormalities identified on HRCT are associated with increased ${ }^{18}$ F-FDG uptake on PET (C).
} 

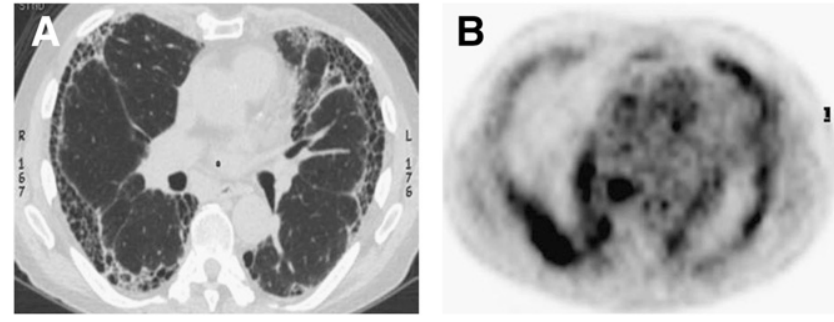

FIGURE 4. HRCT (A) and ${ }^{18} \mathrm{~F}-\mathrm{FDG}$ PET (B) images from 74-y-old man with newly diagnosed IPF. HRCT image (A) shows typical pattern of usual interstitial pneumonitis. Areas of most intense ${ }^{18} \mathrm{~F}$-FDG uptake correspond to areas of parenchymal honeycombing on $\mathrm{CT}$.

and mediastinal lymph node $\mathrm{SUV}_{\max }$ was observed $(r=$ $0.63, P<0.001)$.

\section{Comparison of ${ }^{18}$ F-FDG Metabolism Between Patients} with IPF and Those with Other Types of DPLD

The mean $\mathrm{SUV}_{\max }$ in patients with IPF was $2.9 \pm 1.1$, and in those with other DPLD it was $2.7 \pm 0.9$ (MannWhitney U test, $P=0.862$ ). The mean TBR was $4.4 \pm 1.4$ in patients with typical IPF and $4.3 \pm 1.5$ in other patients (Mann-Whitney $\mathrm{U}$ test, $P=0.681$ ). The mean normal lung $\mathrm{SUV}_{\max }$ was $0.7 \pm 0.2$ in patients with typical IPF and 0.7 \pm 0.2 in other patients (Mann-Whitney U test, $P=0.899$ ).

The mean nodal $\mathrm{SUV}_{\max }$ in patients with IPF was $2.5 \pm$ 1.4 , and in the other DPLD patients the nodal $\mathrm{SUV}_{\max }$ was $3.0 \pm 1.3$ (Mann-Whitney U test, $P=0.268$ ). In patients with IPF, the correlation $(r)$ between pulmonary $\mathrm{SUV}_{\max }$ and nodal uptake was $0.54(P=0.022)$, and for other DPLD patients it was $0.68(P=0.002)$.

The mean uptake $S_{U V} V_{\max }$ of patients with rheumatoid was significantly higher $(3.6 \pm 1.0)$ than that of the rest of the patients, with other forms of non-IPF DPLD $(2.6 \pm 0.5$, Mann-Whitney $\mathrm{U}$ test, $P=0.030$ ).

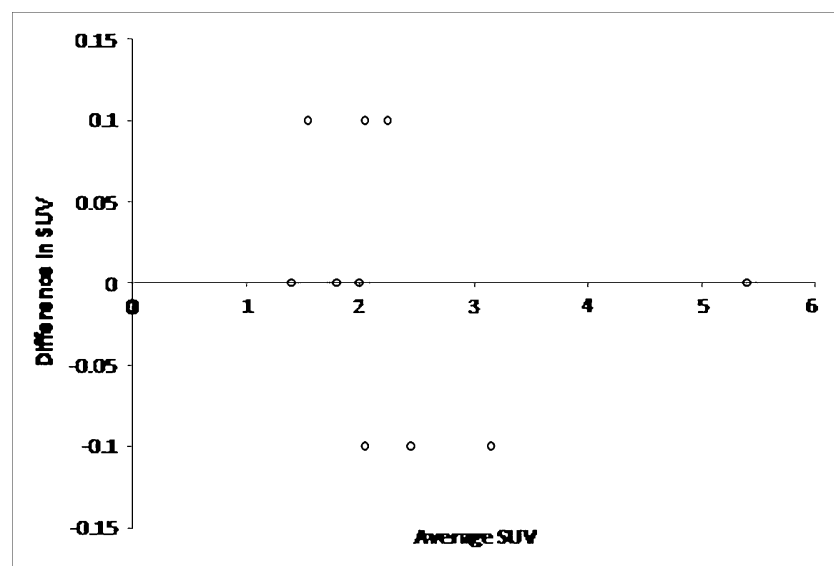

FIGURE 5. Interobserver agreement as assessed by Bland-Altman statistics.
TABLE 3. Maximal Mediastinal Lymph Node ${ }^{18} \mathrm{~F}-\mathrm{FDG}$

Uptake Versus Number of Patients with IPF

$$
\text { SUV }_{\max }
$$

No. of patients

$0.0-0.9$

$1.0-1.9$

$2.0-2.9$

$3.0-3.9$

$4.0-4.9$

5.0 and above

\section{DISCUSSION}

In this prospective study, we presented the first, to our knowledge, PET/CT description in patients with DPLD. In addition, we coregistered the images to HRCT images simultaneously acquired on a PET/64-detector CT instrument. In all the examined patients with DPLD, there were areas of increased ${ }^{18} \mathrm{~F}$-FDG pulmonary metabolism, greater than twice background and quoted normal values for lung (19). The distribution of raised ${ }^{18} \mathrm{~F}-\mathrm{FDG}$ matched the distribution of the lung parenchymal abnormality. In approximately three fourths of the patients, the area of most intense pulmonary ${ }^{18} \mathrm{~F}$-FDG uptake corresponded to regions of honeycombing on HRCT. Such HRCT findings are conventionally believed to be associated with irreversible established fibrotic disease $(12,14-17,20)$; hence, to find PET evidence of increased glucose transporter-1-mediated glucose metabolism at these sites is interesting, especially as these areas showed higher metabolism than did those that were ground-glass predominant. In addition, all but 4 patients showed increased ${ }^{18} \mathrm{~F}$-FDG in mediastinal nodes, which implies that there may be an extrapulmonary component of disease. There were statistically significant relationships between pulmonary ${ }^{18} \mathrm{~F}-\mathrm{FDG}$ uptake and both lung function and global health score.

In this study, raised pulmonary ${ }^{18} \mathrm{~F}-\mathrm{FDG}$ metabolism was associated with ground-glass opacity on HRCT, and groundglass shadowing without architectural distortion on HRCT is associated with inflammation (21). It has been shown that acute inflammatory cells demonstrate increased ${ }^{18} \mathrm{~F}-\mathrm{FDG}$ metabolism in multiple organs including the lung $(7,22$ 25 ); thus, raised ${ }^{18}$ F-FDG metabolism associated with groundglass HRCT changes is not unexpected. However, our findings also indicate that raised pulmonary ${ }^{18} \mathrm{~F}$-FDG metabolism is associated with reticular/honeycombing changes on HRCT,

\begin{tabular}{|c|c|}
\hline SUV $_{\max }$ & No. of patients \\
\hline $0.0-0.9$ & 1 \\
\hline $1.0-1.9$ & 0 \\
\hline 2.0-2.9 & 8 \\
\hline $3.0-3.9$ & 6 \\
\hline $4.0-4.9$ & 2 \\
\hline 5.0 and above & 1 \\
\hline
\end{tabular}


which are conventionally considered to represent established pulmonary fibrosis (26). This association raises the question of whether the morphologic findings of reticulation and honeycombing on HRCT represent burnt-out inert disease or are actually the front line in a metabolically active fibrotic process. It is possible that the raised ${ }^{18} \mathrm{~F}-\mathrm{FDG}$ uptake in patients with changes of honeycombing is a reflection of increased fibroblast metabolism. Fibroblasts are centrally involved in all the proposed models of the pathogenesis of pulmonary fibrosis $(2-8)$ and are recognized to express glucose transporter-1 (27-29). Although the explanation for the raised ${ }^{18} \mathrm{~F}-\mathrm{FDG}$ at sites of honeycombing remains unclear, the findings may suggest that even patients with extensive fibrotic change on HRCT may still be amenable to pharmacologic manipulation. In fact, currently multiple therapeutic agents are being developed to modify fibroblast metabolic response in DPLD $(30,31)$, and in this context it would be useful to search for possible biomarkers of disease activity.

In the absence of histologic verification, it is difficult to speculate on the cellular basis for the raised pulmonary ${ }^{18} \mathrm{~F}-$ FDG uptake in this study. Potential insight, however, can be gleaned from previous work using ${ }^{67} \mathrm{Ga}$-citrate in patients with DPLD. ${ }^{67} \mathrm{Ga}$-citrate uptake is a known marker of pulmonary inflammation and is mediated via transferrin receptors in acute inflammatory cells. ${ }^{67} \mathrm{Ga}$-citrate has been shown to detect pulmonary disease in both early and late DPLD $(32,33)$. Indeed, increased ${ }^{67} \mathrm{Ga}$-citrate uptake was found in asymptomatic family members in patients with familial forms of pulmonary fibrosis (34) and has also been shown to predict pulmonary function (35). Despite demonstrating much potential, ${ }^{67} \mathrm{Ga}$-citrate has more recently been shown to be of limited value in predicting the response to treatment (36). This limitation may be explained in part by the difficulties in quantification of conventional $\gamma$-camera imaging. Thus, the development of PET techniques may be helpful.

Because ${ }^{18} \mathrm{~F}-\mathrm{FDG}$ is also considered a marker for inflammation, some groups have used PET to investigate DPLD in animals. Such studies have provided useful biologic data. For example, there is increasing evidence that PET could have potential for therapeutic monitoring (10). Other PET data have indicated possible cellular mechanisms in DPLD; evidence from 1 study (using ${ }^{18} \mathrm{~F}$ proline rather than ${ }^{18} \mathrm{~F}-\mathrm{FDG}$ ) suggests that polymorphs are responsible for the increased pulmonary tracer uptake in silicosis-induced pulmonary fibrosis in rabbits (9). Another investigation has shown that the ${ }^{18} \mathrm{~F}-\mathrm{FDG}$ uptake appears to occur before these cells reach the alveolar space (8). The increase in ${ }^{18} \mathrm{~F}$-FDG mediastinal lymph node metabolism revealed in our human study is of note. Some have argued that cytokines released by activated macrophage evoke lymphocyte expansion (37); thus, it was interesting that we found that pulmonary ${ }^{18} \mathrm{~F}-\mathrm{FDG}$ uptake reflected the degree of nodal uptake.

Encouraging animal data have been obtained using ${ }^{18} \mathrm{~F}$ FDG PET in DPLD, but translation to humans has been found wanting. In humans, PET has been shown to demonstrate pulmonary inflammation in infective pneumonia (38) and cystic fibrosis (39). Recently, there have been 2 small studies using ${ }^{18} \mathrm{~F}-\mathrm{FDG}$ PET (without CT) in IPF $(40,41)$. In 1 study, there was raised pulmonary ${ }^{18} \mathrm{~F}-\mathrm{FDG}$ in 6 of 7 patients. In 1 patient, changes on PET correlated with a change in clinical status, supporting the use of PET as a monitor of disease activity (40). In the other study (41), ${ }^{18} \mathrm{~F}$-FDG uptake was compared in IPF patients and patients with other forms of interstitial lung disease, and, in keeping with our findings, no difference was found. This result is consistent with hypotheses that propose that although the initial stimulus for the fibrotic process may vary (e.g., IPF or autoimmunity), there is a final common pathway $(2,5,6)$. We have shown the added value of using PET/CT over PET alone $(40,41)$, allowing direct comparison of ${ }^{18} \mathrm{~F}-\mathrm{FDG}$ uptake with the structural appearance of the lung parenchyma and enabling the confident identification of increased metabolism within mediastinal nodes, a finding not described before.

Although we found no significant difference in ${ }^{18} \mathrm{~F}-\mathrm{FDG}$ pulmonary metabolism between different causes of DPLD, there was a wide range of pulmonary ${ }^{18} \mathrm{~F}-\mathrm{FDG}$ metabolism between patients within the otherwise homogeneous subgroup of IPF patients (Table 1). Therefore, it is pertinent to ask whether this variability in uptake values reflects the degree of pulmonary metabolic disturbance. It would be relevant to perform prospective clinical follow-up on patients who underwent PET in a way that has recently been performed using HRCT $(42,43)$. The fact that ${ }^{18} \mathrm{~F}$-FDG uptake did correlate with the global health score and pulmonary physiologic measurements suggests that PET/ CT can discriminate between different degrees of disease severity.

Study limitations include a diverse study population, a function of the heterogeneous nature of DPLD that has made it difficult to investigate. Nonetheless, the IPF 18patient subgroup in this study was homogeneous: All patients in the subgroup had typical clinical, pulmonary physiology and HRCT appearances of IPF, and all were untreated (Table 1). Perfect registration between PET and CT datasets is not always achievable. However, given the large areas of abnormality and the relative ease of visual realignment in cases of less than perfect coregistration, the approach to analysis was sufficiently robust. Although we imaged $1 \mathrm{~h}$ after ${ }^{18} \mathrm{~F}-\mathrm{FDG}$ administration and obtained a good signal, the ideal uptake period in DPLD is yet to be determined. It would have been interesting to have investigated the histologic implications of the ${ }^{18} \mathrm{~F}-\mathrm{FDG}$ PET/CT findings; however, in keeping with current practice guidelines (1-3), biopsies were available only in patients in whom the diagnosis was in doubt. The effect of lung density on measuring pulmonary uptake needs to be appreciated. Clearly in areas of increased lung density, as found in the parenchyma, there would be an expected increase of SUV due to the increase in lung tissue mass. 
From the measured CT values, we were able to estimate the increase of SUV that would result from the increase in density. These estimated values were significantly lower than the measured SUV in the parenchyma (data not shown). Concerning other pulmonary tissue density-related errors, such as those caused by attenuation, correction using measured attenuation should be able to address these. To confirm this, we visually examined both attenuationcorrected and non-attenuation-corrected images, and these images were found to be similar (Fig. 1). In keeping with the development of new techniques, the best form of image analysis is yet to be determined; therefore, for completeness, pulmonary TBR and absolute $\mathrm{SUV}_{\max }$ measurements were made.

\section{CONCLUSION}

This article describes the first, to our knowledge, study of the use of ${ }^{18} \mathrm{~F}-\mathrm{FDG}$ PET/CT for the investigation of DPLD. In all patients, there was raised pulmonary ${ }^{18} \mathrm{~F}-\mathrm{FDG}$ metabolism with a distribution similar to the lung parenchymal abnormality on the coregistered CT image. The findings indicate that increased glucose metabolism is associated with both the ground-glass and the reticulation/ honeycombing HRCT lung changes in DPLD. The metabolism was greater in reticular HRCT parenchymal changes than in the ground-glass changes. There was no demonstrable difference in ${ }^{18} \mathrm{~F}-\mathrm{FDG}$ metabolism between patients with IPF and other forms of DPLD. The pulmonary uptake of ${ }^{18} \mathrm{~F}-\mathrm{FDG}$ on PET significantly correlated with global health score and pulmonary physiologic measurements.

\section{ACKNOWLEDGMENTS}

We thank Professor Brian Hutton (University College London [UCL]) for his advice on image coregistration and on the effects of attenuation on pulmonary ${ }^{18} \mathrm{~F}-\mathrm{FDG}$ uptake. We also acknowledge Professor Mike Peters (Brighton and Sussex Medical School) for his expert advice. This work was undertaken at University College London Hospital/ UCL, which received a proportion of the funding from the United Kingdom's Department of Health's NIHR Biomedical Research Centers funding scheme. A proportion of the funding was received from the Royal College of Radiologists (U.K.).

\section{REFERENCES}

1. American Thoracic Society/European Respiratory Society international multidisciplinary consensus classification of the idiopathic interstitial pneumonias. Am J Respir Crit Care Med. 2002;165:277-304.

2. Gross TJ, Hunninghake GW. Idiopathic pulmonary fibrosis. $N$ Engl J Med. 2001;345:517-525.

3. Dempsey OJ. Clinical review: idiopathic pulmonary fibrosis-past, present and future. Respir Med. 2006;100:1871-1885.

4. Noth I, Martinez FJ. Recent advances in idiopathic pulmonary fibrosis. Chest. 2007;132:637-650.

5. Selman M, King TE, Pardo A. Idiopathic pulmonary fibrosis: prevailing and evolving hypotheses about its pathogenesis and implications for therapy. Ann Intern Med. 2001;134:136-151.
6. Maher TM, Wells AU, Laurent GJ. Idiopathic pulmonary fibrosis: multiple causes and multiple mechanisms? Eur Respir J. 2007;30:835-859.

7. Hunninghake GW, Zimmerman MB, Schwartz DA, et al. Utility of a lung biopsy for the diagnosis of idiopathic pulmonary fibrosis. Am J Respir Crit Care Med. 2001;164:193-196.

8. Jones HA, Cadwallader KA, White JF, Uddin M, Peters AM, Chilvers ER. Dissociation between respiratory burst activity and deoxyglucose uptake in human neutrophil granulocytes: implications for interpretation of ${ }^{18} \mathrm{~F}$-FDG PET images. J Nucl Med. 2002;43:652-657.

9. Wallace WE, Gupta NC, Hubbs AF, et al. Cis-4-[ ${ }^{18}$ F]fluoro-L-proline PET imaging of pulmonary fibrosis in a rabbit model. J Nucl Med. 2002;43:413-420.

10. Chen DL, Schuster DP. Imaging pulmonary inflammation with positron emission tomography: a biomarker for drug development. Mol Pharm. 2006;3:488-495.

11. Lardinois D, Weder W, Hany TF, et al. Staging of non-small-cell lung cancer with integrated positron-emission tomography and computed tomography. $N$ Engl J Med. 2003;348:2500-2507.

12. Littlejohns P, Ebrahim S, Anderson R. Treatment of adult asthma: is the diagnosis relevant? Thorax. 1989;44:797-802.

13. Groves AM, Kayani I, Dickson JC, et al. Oral contrast medium in PET/CT: should you or shouldn't you? Eur J Nucl Med Mol Imaging. 2005;32:1160-1166.

14. Flaherty KR, Toews GB, Travis WD, et al. Clinical significance of histological classification of idiopathic interstitial pneumonia. Eur Respir J. 2002;19:275283.

15. Katzenstein AL, Myers JL. Idiopathic pulmonary fibrosis: clinical relevance of pathologic classification. Am J Respir Crit Care Med. 1998;157:1301-1315.

16. Müller NL, Staples CA, Miller RR, Vedal S, Thurlbeck WM, Ostrow DN. Disease activity in idiopathic pulmonary fibrosis: CT and pathologic correlation. Radiology. 1987;165:731-734.

17. Screaton NJ, Hiorns MP, Lee KS, et al. Serial high resolution CT in non-specific interstitial pneumonia: prognostic value of the initial pattern. Clin Radiol. 2005;60:96-104.

18. Wells AU, Hansell DM, Corrin B, et al. High resolution computed tomography as a predictor of lung histology in systemic sclerosis. Thorax. 1992;47:738-742.

19. Vera P, Ouvrier MJ, Hapdey S, et al. Does chemotherapy influence the quantification of SUV when contrast-enhanced CT is used in PET/CT in lymphoma? Eur J Nucl Med Mol Imaging. 2007;34:1943-1952.

20. Gotway MB, Freemer MM, King TE Jr. Challenges in pulmonary fibrosis. 1: use of high resolution CT scanning of the lung for the evaluation of patients with idiopathic interstitial pneumonias. Thorax. 2007;62:546-553.

21. Remy-Jardin M, Giraud F, Remy J, Copin MC, Gosselin B, Duhamel A. Importance of ground-glass attenuation in chronic diffuse infiltrative lung disease: pathologic-CT correlation. Radiology. 1993;189:693-698.

22. Meller J, Sahlmann CO, Scheel AK. ${ }^{18}$ F-FDG PET and PET/CT in fever of unknown origin. J Nucl Med. 2007;48:35-45.

23. Mamede M, Higashi T, Kitaichi M, et al. $\left[{ }^{18} \mathrm{~F}\right] \mathrm{FDG}$ uptake and PCNA, Glut-1, and hexokinase-II expressions in cancers and inflammatory lesions of the lung. Neoplasia. 2005;7:369-379.

24. Van Waarde A, Cobben DC, Suurmeijer AJ, et al. Selectivity of ${ }^{18}$ F-FLT and ${ }^{18} \mathrm{~F}$ FDG for differentiating tumor from inflammation in a rodent model. $\mathrm{J} \mathrm{Nucl} \mathrm{Med}$. 2004;45:695-700.

25. Goo JM, Im JG, Do KH, et al. Pulmonary tuberculoma evaluated by means of FDG PET: findings in 10 cases. Radiology. 2000;216:117-121.

26. Wells AU, Hansell DM, Rubens MB, Cullinan P, Black CM, du Bois RM. The predictive value of appearances on thin-section computed tomography in fibrosing alveolitis. Am Rev Respir Dis. 1993;148:1076-1082.

27. Hamann A, Benecke H, Greten H, Matthaei S. Metformin increases glucose transporter protein and gene expression in human fibroblasts. Biochem Biophys Res Commun. 1993;196:382-387.

28. Ortiz PA, Haspel HC. Differential control of the functional cell surface expression and content of hexose transporter GLUT-1 by glucose and glucose metabolism in murine fibroblasts. Biochem J. 1993;295:67-72.

29. Tanti JF, Gautier N, Cormont M, Baron V, Van Obberghen E, Le MarchandBrustel Y. Potential involvement of the carboxy-terminus of the Glut 1 transporter in glucose transport. Endocrinology. 1992;131:2319-2324.

30. Williams TJ, Wilson JW. Challenges in pulmonary fibrosis: 7-novel therapies and lung transplantation. Thorax. 2008;63:277-284.

31. Horan GS, Wood S, Ona V, et al. Partial inhibition of integrin $\alpha v \beta 6$ prevents pulmonary fibrosis without exacerbating inflammation. Am J Respir Crit Care Med. 2008;177:56-65.

32. Niden AH, Mishkin FS, Khurana MM. ${ }^{67}$ Gallium citrate lung scans in interstitial lung disease. Chest. 1976; 69(2, suppl)266-268.

33. Tsuchiya Y, Nakao A, Komatsu T, Yamamoto M, Shimokata K. Relationship between gallium 67 citrate scanning and transferrin receptor expression in lung diseases. Chest. 1992;102:530-534. 
34. Bitterman PB, Rennard SI, Keogh BA, Wewers MD, Adelberg S, Crystal RG. Familial idiopathic pulmonary fibrosis: evidence of lung inflammation in unaffected family members. N Engl J Med. 1986;314:1343-1347.

35. Vanderstappen M, Mornex JF, Lahneche B, et al. Gallium-67 scanning in the staging of cryptogenetic fibrosing alveolitis and hypersensitivity pneumonitis. Eur Respir J. 1988;1:517-522.

36. Grijm K, Verberne HJ, Krouwels FH, Weller FR, Jansen HM, Bresser P. Semiquantitative ${ }^{67} \mathrm{Ga}$ scintigraphy as an indicator of response to and prognosis after corticosteroid treatment in idiopathic interstitial pneumonia. J Nucl Med. 2005;46:1421-1426.

37. Warrick JH, Bhalla M, Schabel SI, et al. High-resolution computed tomography in early scleroderma lung disease. J Rheumatol. 1991;18:1520-1528.

38. Jones H, Sriskandan S, Peters A, et al. Dissociation of neutrophil emigration and metabolic activity in lobar pneumonia and bronchiectasis. Eur Respir J. 1997;10:795-803.
39. Chen DL, Ferkol TW, Mintun MA, Pittman JE, Rosenbluth DB, Schuster DP. Quantifying pulmonary inflammation in cystic fibrosis with positron emission tomography. Am J Respir Crit Care Med. 2006;173:13631369.

40. Meissner H, Soo Hoo GW, Khonsary SA, Mandelkern M, Brown CV, Santiago SM. Idiopathic pulmonary fibrosis: evaluation with positron emission tomography. Respiration. 2006;73:197-202.

41. Nusair S, Rubinstein R, Freedman NM, et al. Positron emission tomography in interstitial lung disease. Respirology. 2007;12:843-847.

42. Sumikawa H, Johkoh T, Colby TV, et al. Computed tomography findings in pathological usual interstitial pneumonia: relationship to survival. Am J Respir Crit Care Med. 2008;177:433-439.

43. Best AC, Meng J, Lynch AM, et al. Idiopathic pulmonary fibrosis: physiologic tests, quantitative CT indexes, and CT visual scores as predictors of mortality. Radiology. 2008;246:935-940. 